\title{
Investigating the Influence of Job Satisfaction, Job Burnout and Job Engagement on Turnover Intention Among Private Sector Employees in Saudi Arabia
}

\author{
Abdelmohsen A. Nassani $^{1} \quad$ Abdullah A Alqabbani $^{2} \quad$ Faisal A Alarifi $^{3} \quad$ Mohammad A Almojeiwl $^{4}$ \\ Department of Management, College of Business Administration, \\ King Saud University, P.O. Box 71115, Riyadh 11587, Saudi Arabia
}

\begin{abstract}
This research was conducted on private sector employees in Riyadh, the capital of Saudi Arabia. A quantitative methodology was used with a survey of 336 participants to investigate the influence of job engagement, job satisfaction and job burnout on turnover intention. The results support the research hypotheses that job satisfaction and job engagement negatively influence turnover intention, job burnout has a positive influence on turnover intention, and Job Engagement has a positive influence on job Satisfaction and job burnout.
\end{abstract}

Keywords: Job Satisfaction, Job Burnout, Job Engagement, Turnover Intention.

DOI: $10.7176 / \mathrm{EJBM} / 13-10-13$

Publication date:May $31^{\text {st }} 2021$

\section{Introduction}

Turnover Intention can be defined as an employee's intention to quit an organization (Saks, 2006). Employee turnover is one of the most critical issues that need to be addressed by the organization leaders and if possible, be avoided. On the other hand, turnover intention means the employee's intention to leave the organization or the employee's willingness to leave his job. Turnover intention is a big challenge that faces the organizations over the world. Although, there are many researches have investigated on this problem, but There is no positive impact has been showed on employee turnover rate (Rizwan et al., 2014).

Employee turnover can impact the organization in many different aspects. It can be costly to the organization, because the organization will have to recruit and hire new employees and sending them for training, and that absolutely cost the organization a lot especially for a very technical job. It may also impact the productivity of other employees because when the employee leaves the organization, other employees will have to work more to cover the workload of the employee who left, and organizations may have to pay overtime to other employees to work for more hours. Employee turnover has also an impact on the organization culture and workload of other employees. Other employees who are overworked and disengaged are more prone to burnout, which leads to increased turnover. It is hard to disregard the fact that employee who leave their jobs unsatisfied will be telling their stories to other people outside, which can affect the organization reputation.

The results of a recent study conducted by the Public Opinion Polls Unit at the King Abdulaziz Center for National Dialogue on organizational loyalty among workers in Saudi Arabia found that 22.4 percent of employees are considering not continuing to work in the current organization. The percentage of government employees was 13.5 percent, and the percentage of private sector employees was 8.9 percent, while 41.8 percent of government employees reported that they often think of continuing with the current organization, but 41.7 percent of employees think about leaving their jobs for a better opportunity.

Today, Saudi Arabia is reforming its economy to become more familiar with new developments in the global market. Organizations that aim for a high international market share have a low employee turnover rate and a high employee commitment, which is linked to efficiency, hard work, and better work quality. (Al-Kahtani, 2002). According to (Achoui \& Mansour, 2007), benefits and salaries are higher in the private sector, however, job security is lower. A study on employee turnover in Saudi organizations found that turnover is high in the Saudi market, especially in the private sector. The Saudi government's Saudization policy pushes many organizations to achieve the mandatory percentage of Saudi national in their organizations. Furthermore, economic growth in the private sector drives organizations to recruit and hire more qualified Saudis at the expense of other firms. The preceding factors all played an important role in Saudi Arabia's turnover issue. An empirical survey conducted by Achoui and Mansour (2007) to classify the main causes of employee turnover in Saudi organizations, and most respondents confirmed that their organizations are not assisting them in retaining employees.

This study will add to the subject in many ways. First, there have been limited research on whether job engagement and job burnout are associated with turnover intention among private sector employee in Saudi Arabia. Second, there have been limited published study has been found that include job satisfaction and job burnout in the same model with turnover intention. Finally, this study will investigate the relationships between job engagement and between job satisfaction, job burnout, and turnover intention.

The purpose of this study is to verify that turnover intention is influenced directly by job engagement, job 
satisfaction, and job burnout. It also aimed to analyses the mediating role of job satisfaction, and job burnout between job engagement and Turnover Intention among private sectors employees in Saudi Arabia. Employee turnover can have a significant impact on organizations.

\section{Literature Review and Hypotheses Development}

\subsection{The Relationship between Job Satisfaction and Turnover Intention}

Turnover intention is simply can be defined as the intention of an employee to leave his or her current job. Intentions are important to investigate because they predict an employee's perception and judgment. (Mobley et al., 1979). Job Satisfaction is one of the most aspects that have been defined and debated due to the importance of this aspect for both employees and organization. Job Satisfaction can be defined as the employee's feeling towards his or her job, which affects his or her performance, either positively or negatively.

The importance of Job Satisfaction is that it measures the employee's feeling and to which extent the employee is satisfied or dissatisfied. If we look over other definitions, we will find that it indicates that to the emotional reaction of the employee to his or her job. For instance, job satisfaction has been defined as the degree to which employees have a positive affective orientation toward employment by the organization (Price, 1997). According to (Spector, 1997), Employee job satisfaction is associated with how people perceive, think, and feel their jobs. Another one defines Job Satisfaction as the feeling that a worker has about his job or a general attitude towards work or a job and it is influenced by the perception of one's job. Reilly (1991).

According to Mobley (1977), job satisfaction is most frequently thought about and studied in relation to turnover intention. The study found that job dissatisfaction can lead to the behavior of looking for new jobs, and turnover intention can be used to expect turnover behavior. Many prior studies have shown that job satisfaction is strongly influence on turnover intention. One of those studies was on employees in a manufacturing company in Indonesia, claimed there is a direct correlation between an employee's job satisfaction and turnover intention (Tarigan and Wahyu Ariani (2015). The same result found when Batura et al. (2016) studied the relationship between employee job satisfaction and turnover intention in the healthcare industry. Another study supports the same result when Adeyemo and Afolabi (2007) found a negative correlation between job satisfaction and withdrawal cognition, or intention to quit. Also, Huffman, Casper, and Payne (2014) found a correlation between turnover and a reduction in job satisfaction. There is a study conducted by Sheraz, Wajid, Sajid, Quershi, and Rizwan (2014) on more than 200 professional workers in Pakistan. The findings of the study showed a negative correlation between job satisfaction and turnover intention. Many prior studies have shown that job satisfaction is strongly affect turnover intention. One of those studies was on employees in a manufacturing company in Indonesia, claimed there is a direct correlation between an employee's job satisfaction and turnover intention (Tarigan and Wahyu Ariani (2015). The same result found when Batura et al. (2016) studied the relationship between employee job satisfaction and turnover intention in the healthcare industry. Another study supports the same result when Adeyemo and Afolabi (2007) found a negative correlation between job satisfaction and withdrawal cognition, or intention to quit. Also, Huffman, Casper, and Payne (2014) found a correlation between turnover and a reduction in job satisfaction.

There are many factors can lead employees to be satisfied or dissatisfied including attractive pay, rewards, career development, appreciation, job security, and many other important factors which absolutely can lead to employee satisfaction or dissatisfaction. As nature of human beings, if the employee is not satisfied, he/she will have intention to leave the organization and find another opportunity outside. The more employees are not satisfied, the more turnover intentions are increased and then it could be costly to the organization when the employees leave.

When an employee is not satisfied with the job or organization, the employee has a greater chance of leaving the organization (Kim \& Park, 2014). To reduce turnover intention, employees need to feel satisfied with their jobs and the organization. Sheraz, Wajid, Sajid, Quershi, and Rizwan (2014). Roshidi (2014) found that most previous theories and research establish that job satisfaction is one of the key variables expected relationship with turnover intention.

In addition, according to Zulbahari and Alias (2014), Job satisfaction can also influence the employee's decision to stay or leave the organization. Job dissatisfaction will cause the employee to consider leaving their current job and moving to another job. If the employees are very satisfied with their current job, they will stay longer in the organization. However, if the employees are dissatisfied and can start a new job in another organization, they will leave the organization. Black \& D. Wiliam (2013) also found that job satisfaction has negative and significant relationship with turnover intention.

Based on the study conducted within this research, it has been found that there is a negative influence between job satisfaction and turnover intention.

\section{H1: Job Satisfaction will negatively influence Turnover Intention.}




\subsection{The Relationship between Job Burnout and Turnover Intention}

Burnout is a comprehensive concept created by Freudenburger in Clinical Psychology (1974). According to Maslach C. (1981), burnout, which results from continuous work pressure that is not effectively managed, includes the following three dimensions: emotional exhaustion, depersonalization, and reduced personal accomplishment. Job burnout has been described as a social problem that has existed for a long time and has several expressions that vary depending on the period, researchers, in different countries and languages (Schaufeli et al., 2009). Job burnout is a condition caused by persistent vulnerability to stress at work. It has many costs to the organization and the employees themselves. The value of job burnout is outlined by its association with various types of unfavorable organizational outcomes, various types of health problems, and mental health problems (Cordes and Dougherty, 1993; Maslach and Leiter, 2016; Schaufeli and Buunk, 2003; Shirom and Melamed, 2005). Burnout is one of the highly scrutinized negative outcomes (Keel, 1993), describing a wide range of behaviors and attitudes of employees in high-stress workplaces (Lee \& Ashforth,1996).

Furthermore, rich evidence has suggested that turnover intention is more likely to occur for employees with high-degree burnout in many professions (Huang IC, Chuang CHJ, and Lin HC,2003), (Shimizu T, Feng QL, Nagata S, 2005). Burnout has been associated with various and diverse forms of turnover; thus, the various forms of turnover include intention to leave, actual turnover, and absenteeism (Leiter Michael \& Maslach, 2009). Given the significant evidence, turnover intention is more likely for those employees who exhibit high levels of burnout in numerous careers (Huang, Chuang, \& Lin, 2003; Shimizu, Feng, \& Nagata, 2005).

Significant and intense job stress and low job satisfaction were associated with high burnout, especially in the aspects of emotional exhaustion and depersonalization. Two elements, namely low job satisfaction and high emotional exhaustion, were associated with high employee turnover intention (Lin, Jiang, \& Lam, 2013).

According to the previous literatures, the second hypothesis in this study assumes a positive influence between job burnout and turnover intention.

\section{H2: Job burnout will Positively influence Turnover Intention.}

\subsection{The Relationship between Job Engagement and Turnover Intention}

Employee engagement is the extent to which employees are emotionally and mentally connected and committed to the organization and its vision and objectives. According to Kevin Kruse, "Employee engagement is the employee's emotional attachment to the organization and its goals. Employee engagement is a positive state of mind that leads to a happy and motivated employee (Ran Xiong \& Yuping Wen 2020).

Leaders all over the world are struggling to increase the level of engagement of their employees. We can see that employees, especially Millennials, get bored easily with their work and start looking for new job opportunity and new challenge just to have their interests back. The Corporate Leadership Council says that engagement is employees' commitment to their organization, how hard they work, and how long they stay because of that commitment. They say that high engagement employees put in $57 \%$ more effort, perform $20 \%$ better, and are $87 \%$ less likely to leave than low engagement employees.

According to the Society for Human Resource Management (SHRM), employees fall into three categories as following:

- Actively disengaged: busy acting out their unhappiness and undermining what the organization is trying to accomplish.

- Disengaged: “sleepwalking' through their day and putting time, not passion, into work.

- Engaged: working with passion and feeling a real connection to the organization.

Turnover is the process of losing talents in the workforce and replace them by new hires. Employee turnover is one of the most critical issues that need to be addressed by the organization leaders and if possible, be avoided. On the other hand, turnover intention means the employee's intention to leave the organization or the employee's willingness to leave his job.

Turnover intention can be measured by anticipating on whether employees are planning to leave their positions or whether organizations are trying to remove some of their current employees. Turnover intention can be linked to several factors and causes. It can be related to the employees themselves or to other factors caused by the organization (Sandhya S \& Sulphey M M, 2020)

Previous studies found out that job engagement is negatively influence turnover intention (Alacron \& Edwards, 2010; Shuck, Reio \& Rocco, 2011). If employees are engaged to their jobs, they are less likely to think about leaving or changing their jobs. In addition, job engagement and work-life-balance have a strong relationship with turnover intention (Kristen Schilling 2014). Also, job engagement clearly predicted turnover intentions and job satisfaction levels (Gene M. Alarcon and Jean M. Edwards 2010).

Based on these previous research works, the third hypothesis in this study proposes a negative influence between job engagement and turnover intention.

\section{H3: Job Engagement will negatively influence turnover intention.}




\subsection{The Relationship between Job Engagement and Job Satisfaction}

Employee engagement is the extent to which employees are emotionally and mentally connected and committed to the organization and its vision and objectives. According to Kevin Kruse, "Employee engagement is the employee's emotional attachment to the organization and its goals. Employee engagement is a positive state of mind that leads to a happy and motivated employee (Ran Xiong \& Yuping Wen 2020).

Job satisfaction can be defined as the extent to which employee feel satisfied and motivated with the job content and outputs. When employees are satisfied, they become more productive, faithful, and committed to their organizations (Khin Thet Htar Swe \& Lee Hsing Lu 2019).

Many scholars have explored and touched on the essence of the relationship between the variables, stating that employees who are happy with their employment may not be engaged, but staff who are engaged and believe in the organization's ideals will almost definitely be satisfied with their jobs. Employee engagement involves things like autonomy, development, control, and communication, while job satisfaction is more transactional. By adopting the engagement model, organizations can achieve high levels of productivity and job satisfaction, as well as a sense of belonging and commitment to the company (Roheel, Jain, \& Balu, L. 2018).

Job satisfaction, on the other hand, has been shown to have a strong association with employee involvement, implying that satisfaction is a significant guide to achieving employee engagement. (Malhotra, 2017).

In a previous study, Lodahl \& Kejner (1965) found that meaningfulness of work and adequacy of supervision affect job satisfaction. According to another previous study Harter (2002), based on 7,939 business units in 36 companies, examined the link between employee satisfaction and engagement and the business unit outcomes in terms of productivity, profit, customer satisfaction, employee turnover and employee accidents. They have found significant and strong correlations between employee satisfaction and engagement and the business unit outcomes. Based on these previous research works, our fourth hypothesis propose a positive relationship between job engagement and job satisfaction.

\section{H4: Job Engagement will positively influence Job Satisfaction.}

\subsection{The Relationship between Job Engagement and Job burnout}

As discussed earlier in this study, job burnout is a condition caused by persistent vulnerability to stress at work. It has many costs to organizations and employees themselves. Job engagement can also be defined as the extent to which an individual mentally accepts work; or the importance of work in the mind of the individual (Sonnentag, 2003).

A high level of job performance often requires a high level of job engagement, in the other hand, a high level of job engagement also might lead to burnout. When an employee devotes too much energy to work, it can cause the phenomenon of job burnout. organizations be aware to the phenomenon of job burnout, which is caused by a high level of job engagement of the employees while requiring employees to work hard. When the burnout occurs among employees, they lack motivation to work. In a company, if the employees have a feeling of job burnout because they work exhausted and tired for a long time, it will have certain effects on the individual work performance of the employees and the operational performance of the company. Job burnout would affect the individual's body, mind, and work and the performance of the organization in which the individual was working (Wong, 2000).

If individuals put too much energy into work, they will feel sick from work, and this can lead to job burnout. Those who are engaged too much and see the job as the main part of their life are more apt to feel emotional exhaustion. This is because when too much importance is placed on the job and the outcome of the job, a high level of stress is caused, so job burnout can easily occur (Schaufeli, Bakker, \& Rhenen, 2009).

According to the above literature reviews, the study hypothesizes that high levels of job engagement will cause employees to generate negative feelings and emotions, and they will be fed up with the job, which may lead to job burnout, therefore, the following hypothesis is proposed:

\section{H5: Job Engagement will positively influence Job burnout.}

\subsection{Research Model}

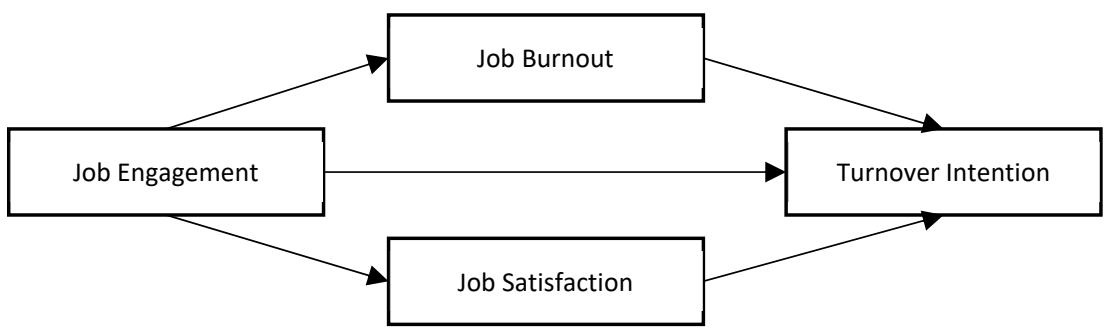

Figure 1. The Research Model 


\section{Methods}

\section{1 participants}

This research was carried out on private sector employees in Riyadh, the capital of Saudi Arabia. By using the formula of Richard Geiger and considering the official statistical population 2020, the final sample size was 336 participants.

\subsection{Measures}

\subsubsection{Job Satisfaction}

The questionnaire used a job satisfaction scale according to Mak \& Sockel (1999). It is a scale with 4 items, but to increase reliability we have narrowed down to 3 items. The scale rated on a 5-point Likert scale ranging from 1 (never) to 5 (always).

3.2.2 Job Burnout

The Maslach Burnout Inventory scale was used in the questionnaire to measure job burnout (Maslach \& Jackson, 1986). It is a scale of 22 items rated on a 5-point Likert scale ranging from 1 (never) to 5 (always).

3.2.3 Job Engagement

The questionnaire assessed job engagement by Utrecht Work Engagement Scale (UWES) (Schaufeli et al., 2002). It a scale of 17 items rated on a 5-point Likert scale ranging from 1 (never) to 5 (always).

3.2.4 Job Engagement

The questionnaire used a turnover intention scale according to Mak \& Sockel (1999). It is a scale with 4 items rated on a 5-point Likert scale ranging from 1 (never) to 5 (always).

\subsection{Reliability}

Table 1 . The reliability test results.

\begin{tabular}{|l|c|c|}
\hline Scale & Cronbach's Alpha & N.O. of Items \\
\hline Job Satisfaction & 0.713 & 3 \\
\hline Turnover Intention & 0.828 & 4 \\
\hline Job Engagement & 0.940 & 17 \\
\hline Job burnout & 0.857 & 22 \\
\hline
\end{tabular}

Cronbach's alpha $(\alpha)$ is between $0.713-0.940$, which indicates a high level of internal consistency for our scales. Higher values of Cronbach's alpha are better, although all recommended values are 0.7 or higher (DeVillis, 2003; Kline, 2005).

\section{Results}

The analysis within the research has been applied using the Statistical Package for the Social Sciences (SPSS) version 26 and Analysis of Moment Structures (AMOS) version 26. At the primary stage of analyzing the information, it is checked for inconsistent responses. Then, correlation variables were computed for correlations between quantitative variables. Regression analyses were performed on all variables, then a path analysis technique was utilized to see the best model fit.

\subsection{Descriptives Statistics}

Table 2. Descriptives Statistics results.

\begin{tabular}{|l|c|c|c|c|c|}
\hline Variables & $\mathrm{N}$ & Minimum & Maximum & Mean & Std. Deviation \\
\hline Job Satisfaction (JS) & 336 & 1.00 & 5.00 & 3.4534 & .92746 \\
\hline Turnover Intention (TI) & 336 & 1.00 & 5.00 & 3.6548 & 1.05813 \\
\hline Job Burnout (JB) & 336 & 1.00 & 5.00 & 3.8280 & .77780 \\
\hline Job Engagement (JE) & 336 & 1.95 & 5.00 & 3.2655 & .58861 \\
\hline Valid N (listwise) & 336 & \multicolumn{1}{|l|}{} & & \\
\hline
\end{tabular}

Table 2 shows the descriptive statistics of the results. The mean scores of all variables ranged from $3.83-$ 3.27. The highest mean score was for job burnout, while the lowest mean score was for job engagement. Standard Deviation is also shown in this table with values ranging from 0.59 to 1.06 . 


\subsection{Correlations}

Table 3. The table of correlation

\begin{tabular}{|l|c|c|c|c|}
\hline \multicolumn{5}{|c|}{ Pearson Correlations } \\
\hline Variables & Job Satisfaction & Turnover Intention & Job Engagement & Job burnout \\
\hline Job Satisfaction & & $-.472^{* *}$ & $.561^{* *}$ & -.084 \\
\hline Turnover Intention & $-.472^{* *}$ & & $-.289^{* *}$ & $.389^{* *}$ \\
\hline Job Engagement & $.561^{* *}$ & $-.289^{* *}$ & & .102 \\
\hline Job Burnout & -.084 & $.389^{* *}$ & .102 & \\
\hline$* *$ Correlation is significant at the 0.01 level (2-tailed).
\end{tabular}

The relationships between the variables can be seen in the correlation table. Job satisfaction and intention to leave have a clear negative relationship (- 0.47). Job Burnout and Turnover Intention, on the other hand, have a good positive relationship (0.39). In addition, the table shows that Job Engagement and Turnover Intention have a negative association (-0.29), as well as the relationship between job satisfaction and job burnout (-0.08). The results show a strong association between job Engagement and Job Burnout (0.10), as well as Job Engagement and Job Satisfaction (0.56).

\subsection{Regression}

Table 4. The table of Model Summary

\begin{tabular}{|l|c|c|c|c|}
\hline \multicolumn{5}{|c|}{ Model Summary } \\
\hline Model & R & R Square & Adjusted R Square & Std. Error of the Estimate \\
\hline 1 & 0.595 & 0.354 & 0.348 & 0.85409 \\
\hline a. Predictors: (Constant), Job Burnout, Job Satisfaction, Job Engagement \\
\hline
\end{tabular}

Table 5. The table of ANOVA results

\begin{tabular}{|c|c|c|c|c|c|c|}
\hline \multicolumn{7}{|c|}{ ANOVAa } \\
\hline \multicolumn{2}{|c|}{ Model } & Sum of Squares & $\mathrm{df}$ & Mean Square & $\mathrm{F}$ & Sig. \\
\hline \multirow[t]{3}{*}{1} & Regression & 132.895 & 3 & 44.298 & 60.727 & $<.001$ \\
\hline & Residual & 242.182 & 332 & .729 & & \\
\hline & Total & 375.077 & 335 & & & \\
\hline \multicolumn{7}{|c|}{ a. Dependent Variable: Turnover Intention } \\
\hline
\end{tabular}

Table 6. The table of coefficients

\begin{tabular}{|c|c|c|c|c|c|c|}
\hline & & & Coefficients & & & \\
\hline & & $\mathrm{B}$ & Std. Error & Beta & $\mathrm{t}$ & Sig. \\
\hline 1 & (Constant) & 3.570 & .347 & & 10.296 & $<.001$ \\
\hline & Job Satisfaction & -.429 & .062 & -.376 & -6.956 & $<.001$ \\
\hline & Job Engagement & -.157 & .074 & -.115 & -2.133 & .034 \\
\hline & Job Burnout & .664 & .081 & .369 & 8.206 & $<.001$ \\
\hline
\end{tabular}

From tables number 4,5 , and 6 , a multiple regression was run to predict the level of the turnover intention from job burnout, job satisfaction and job engagement. The multiple regression model statistically significantly predicted the level of the turnover intention, $\mathrm{F}=60.727$. R2 for the overall model was $35.4 \%$ with an adjusted R2 of $34.8 \%$, This means that the addition of all our independent variables into a regression model explained $34.8 \%$ of the variability of our dependent variable.

All three variables added statistically significantly to the prediction. From the Coefficients table we can see that coefficient for job burnout is 0.37 , which means increasing one point of the level of job burnout will increase in average 0.4 point approximately in turnover intention. While increasing one point of job satisfaction will lead to less turnover intention by around 0.37 point. Also increasing one point of job engagement will lead to less turnover intention by around 0.11 point.

\subsection{Research Model Fit}

Path analysis was applied to test the study's hypotheses. The following tables reflect the fit indices from the default model which shows that the default model is the perfect fit for goodness fit. 


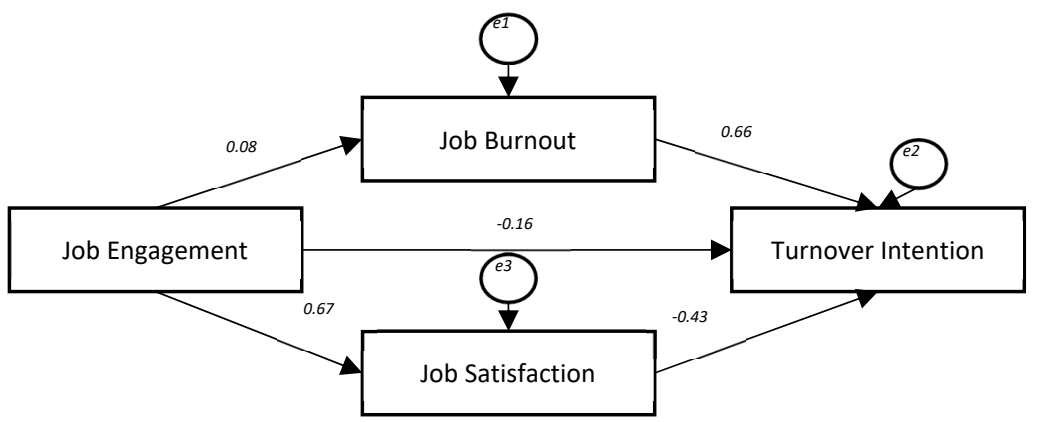

Figure 2. The Path Analysis

Table 7. The Fit Indices

\begin{tabular}{|l|c|c|c|c|c|c|c|}
\hline Model & Chi-square & DF & RMSEA & CFI & GFI & AGFI & NFI \\
\hline Default model & 9.943 & 1 & 0.163 & 0.968 & 0.986 & 0.856 & 0.965 \\
\hline RMSEA, Root Mean Square Error of Approximation. \\
$\begin{array}{l}\text { CFI, Comparative Fit Index. } \\
\text { GFI, Goodness-of-fit. }\end{array}$ \\
AGFI: Adjusted goodness-of-fit. \\
\hline
\end{tabular}

Table 8. The Standardized Effects in the Default Model

\begin{tabular}{|l|c|c|c|c|c|c|c|c|c|}
\hline \multirow{2}{*}{ Variables } & \multicolumn{3}{|c|}{ Job Engagement } & \multicolumn{3}{c|}{ Job Satisfaction } & \multicolumn{3}{c|}{ Job Burnout } \\
\cline { 2 - 11 } & D.E. & I.E. & T.E. & D.E. & I.E. & T.E. & D.E. & I.E. & T.E. \\
\hline Job Satisfaction & 0.56 & 0.00 & 0.56 & 0.00 & 0.00 & 0.00 & 0.00 & 0.00 & 0.00 \\
\hline Job Burnout & 0.10 & 0.00 & 0.10 & 0.00 & 0.00 & 0.00 & 0.00 & 0.00 & 0.00 \\
\hline Turnover Intention & -0.11 & -0.18 & -0.29 & -0.38 & 0.00 & -0.38 & 0.38 & 0.00 & 0.38 \\
\hline
\end{tabular}

D.E., Direct Effect; I. E.,Indirect Effect; T. E., Total Effect

The two previous tables show the result of path analyses, which aimed to test the research hypotheses. The table 7 shows the fit indices from the default model: Root Mean Square Error of Approximation (RMSEA) is 0.16, Comparative Fit Index (CFI) is 0.99, Goodness-of-fit (GFI) is 0.99, Adjusted goodness-of-fit (AGFI) is 0.87, and Normed-fit index (NFI) is 0.97 . The indices results that the default model is that the perfect appropriate goodness fit. The coefficients that are shown in Table 8 refer that there is a positive direct effect by job engagement on job satisfaction and job burnout, whereas it has a negative direct effect on turnover intention. Turnover Intention has been affected directly by job satisfaction in negative way and by job burnout in positive way. The results show that job engagement has a direct positive effect on job satisfaction and job burnout and has an indirect negative effect on turnover intention through the mediating effect of job satisfaction and job burnout.

\section{Discussion}

This study developed five hypotheses about the influence of job burnout, job engagement, and job satisfaction on turnover intention among employees in the private sector in Riyadh. The findings of this study support all these hypotheses.

Zulbahari and Alias (2014), in their study concluded that Job satisfaction can influence the employee's decision to stay or leave the organization. Job dissatisfaction will cause the employee to consider leaving their current job and moving to another job. If the employees are very satisfied with their current job, they will stay longer in the organization. However, if the employees are dissatisfied and can start a new job in another organization, they will leave the organization. The result of our study supports these findings by show that job satisfaction has a direct negative influence on turnover intention which also supports what Black \& D. Wiliam (2013) find that job satisfaction has negative and significant relationship with turnover intention.

When it is come to the relationship between job burnout and turnover intention, Huang IC and others (2003) discussed that rich evidence has suggested that turnover intention is more likely to occur for employees with highdegree burnout in many professions. While Leiter Michael and Maslach (2009) argue that burnout has been associated with various and diverse forms of turnover; thus, the various forms of turnover include intention to leave, actual turnover, and absenteeism. Given the significant evidence, turnover intention is more likely for those employees who exhibit high levels of burnout in numerous careers (Shimizu, Feng, \& Nagata, 2005). Our study by its findings concludes that job burnout has a direct positive influence on turnover intention.

Previous studies found out that job engagement is negatively influence turnover intention (Alacron \& Edwards, 2010; Shuck, Reio \& Rocco, 2011). Kristen Schilling (2014) states in her study If employees are engaged to their jobs, they are less likely to think about leaving or changing their jobs. In addition, job engagement and 
work-life-balance have a strong relationship with turnover intention. Our findings support the previous studies by concluding that job engagement is negatively influence turnover intention.

Malhotra (2017), found that Job satisfaction, has been shown to have a strong association with employee involvement, implying that satisfaction is a significant guide to achieving employee engagement. Khin Thet Htar Swe \& Lee Hsing Lu When (2019) argue that when employees are satisfied, they become more productive, faithful, and committed to their organizations. The findings of this current study agree with the Literature review by showing that there is a positive correlation between Job engagement and job satisfaction.

Schaufeli, Bakker, and Rhenen (2009), argued that if individuals put too much energy into work, they will feel sick from work, and this can lead to job burnout. Our research results find that there is a positive relation between job engagement and job burnout. Those who are engaged too much and see the job as the main part of their life are more apt to feel emotional exhaustion. This is because when too much importance is placed on the job and the outcome of the job, a high level of stress is caused, so job burnout can easily occur.

\section{Limitations}

This study focused on the employees in the private sector in Riyadh, which might make the results limited. However, the survey was designed with scales have the smaller number of items in order to increase participants to gain an appropriate size of sample. The items used in the survey was translated to Arabic to match with participants, which might decrease the accuracy.

\section{Recommendations}

\section{1. implications}

The study provides managerial insights on turnover intention relations with other variables, which help organizations in their plans to retain their talents. The results establish the importance of job engagement and job satisfaction in decreasing turnover rate. On the other side, the results find that burnout leads employees to turnover.

\subsection{Future Research}

The area of this study is particularly important. We recommend in the further researches to use other measurements with higher degree of reliability to study the influence of Job Satisfaction, Job Burnout and Job Engagement on Turnover Intention. It is also recommended to study larger geographical areas to draw generalizable conclusions.

\section{Conclusions}

In the literature review, many studies found a remarkable relationship affecting turnover intention. Achoui and Mansour (2007) state that there is a study conducted on employee turnover in Saudi organizations confirmed that the amount of turnover in Saudi market is high, particularly in the private sector. One of the ways that this study aimed to add to the subject is enriching the limited field of researching on whether job engagement, job satisfaction, and job burnout are associated with turnover intention among private sector employee in Saudi Arabia. The results support the five hypotheses that were developed in this study.

To sum up, five points can conclude the findings of the study. First, job satisfaction negatively influences turnover intention. Second, job burnout positively influences turnover intention. Third, job engagement negatively influences turnover intention. Fourth, job engagement positively influences job satisfaction. Finally, job engagement positively influences Job burnout.

\section{References}

Adeyemo, D. A., \& Afolabi, J. O. (2007). Influence of sexual harassment, occupational stress, emotional intelligence, and job satisfaction on withdrawal cognition of female practitioners in Oyo sate, Nigeria. Pakistan Journal of Social Sciences, 4(4), 639-464.

Achoui, M., \& Mansour, M. (2007). Employee Turnover and Retention Strategies: Evidence from Saudi Companies. International Review of Business Research Papers, 3(3), 1-16.

Al-Kahtani, A. S. (2002). Organizational loyalty of Saudi employees in Saudi organizations. Global Competitiveness.

Batura, N., Skordis-Worrall, J., Thapa, R., Basnyat, R., \& Morrison, J. (2016). Is the job satisfaction survey a good tool to measure job satisfaction amongst health workers in Nepal? Results of a validation analysis. BMC Health Services Research, 16(1), 1-13. doi:10.1186/s12913-016-1558-4.

Brad Shuck, Thomas G. Reio, Tonette E Rocco. (2011). Employee engagement: An examination of antecedent and outcome variables.

Cranny, C.J., Smith, P.C., \& Stone, E.F. (1992). Job satisfaction. New York: Lexington Books.

Huffman, A.H., Casper, W.J., \& Payne, S.C. (2014). How does spouse career support relate to employee turnover? Work interfering with family and job satisfaction ascmediators, Journal of Organizational Behavior, 35(2), 194-212. doi:10.1002/job.1862. 
Chang, Black, P., and Wiliam, D. (2013). Inside the Black Box: Raising Standards Through Classroom Assessment. Wiley Online Library, 80(2), 139-148. https://doi.org/10.1002/hrm.

Freudenberger HJ: Staff burnout. Journal of Social Issues 1974, 30:159-165.

Huang IC, Chuang CHJ, Lin HC: The role of burnout in the relationship between perceptions of organizational politics and turnover intentions. Public Personnel Management 2003, 4:519-531.

Hassan, Roshidi. (2014). Factors Influencing Turnover Intention Among Technical Employees in Information Technology Organization: A Case of Xyz (M) Sdn. Bhd. International Journal of Arts and Commerce, Vol. 3 No. (2008), 120-137.

Huffman, A.H., Casper, W.J., \& Payne, S.C. (2014). How does spouse career support relate to employee turnover? Work interfering with family and job satisfaction as mediators, Journal of Organizational Behavior, 35(2), 194-212. doi:10.1002/job.1862.

Gene M. Alarcon \& Jean M. Edwards. (2010). The Relationship of Engagement, Job Satisfaction and Turnover Intentions.

Kim, S., \& Park, S. (2014). Determinants of job satisfaction and turnover intentions of public employees: Evidence from US federal agencies. International Review of Public Administration, 19(1), 63-90. doi:10.1080/12294659.2014.887354.

Kristen Schilling. (2014), The relationship between job engagement, work interference with personal life, and turnover intentions.

Khin Thet Htar Swe \& Lee Hsing Lu (2019). The Enhancement of Employee Engagement to Reduce Employee Turnover Intention and Improve Employee Job Satisfaction: An Action Research on Mirac Company in Yangon, Myanmar.

Lu Lu, Allan Cheng Chieh Lu, Dogan Gursoy, Nathan Robert Neale. (2015) Work engagement, job satisfaction, and turnover intentions. A comparison between supervisors and line-level employees.

Maslach C, Jackson SE: The measurement of experienced burnout. Journal of Occupational Behavior 1981

Mobley, W. H. (1977). Intermediate Linkages in the relationship between job satisfaction and employee turnover, Journal of Applied Psychology, 62(2), 237-240

Mobley, W.H., Griffeth, R.W., Hand, H.H., \& Meglino, B.M. (1979), „Review and concept analysis of the employee turnover process ${ }^{\text {ee }}$, Psychological Bulletin, Vol 14, pp 224-247.

Nwokolo, C., \& Anyamene, A. (2016). Relationship between job satisfaction and commitment among secondary school counsellors in Anambra State, Nigeria. European Journal of Education Studies, 0. doi:10.5281/zenodo.58527.

Price, J. L. (1997). Handbook of organizational measurement. International Journal of Manpower, 18, 303-558.

Public Opinion Polls Unit at the King Abdulaziz Center for National Dialogue (2014), Organizational loyalty among workers in Saudi Arabia.

Rizwan, M., Arshad, M. Q., Munir, H. M. A., Iqbal, F., and Hussain, A. (2014). Determinants of Employees intention to leave: A Study from Pakistan. International Journal of Human Resource Studies, 4(3), 1-19.

Ran Xiong \& Yuping Wen (2020). Employees' turnover intention and behavioral outcomes: The role of work engagement.

Sandhya S \& Sulphey M M (2020). Influence of empowerment, psychological contract and employee engagement on voluntary turnover intentions.

Reilly, C. R. (1991) Organizational Behavior. Annual Review of Psychology, 427- 458.

Saks, A.M. (2006) 'Antecedents and consequences of employee engagement', Journal of Managerial Psychology, 21(7): 600-619.

Shimizu T, Feng QL, Nagata S: Relationship between turnover and burnout among Japanese hospital nurses. Journal of Occupational Health 2005, 4:335.

Spector, P. (1997), Satisfaction: Application, Assessment, Causes and Consequences, Sage, London.

Sheraz, A., Wajid, M., Sajid, M., Quershi, W., \& Rizwan, M. (2014). Antecedents of job stress and its impact on employee's job satisfaction and turnover intentions. International Journal of Learning \& Development, 4(2), 204-226.

Tarigan, V., Wahyu Ariani, D. (2015). Empirical study relations job satisfaction, organizational commitment, and turnover intention. Advances in Management \& Applied Economics, 5(2), 21-42, 1792-7544.

Xuewen Zhang1,2, Liyan Bian2, Xue Bai2, Dezhong Kong2, Li Liu1, Qing Chen1 and Ningxiu Li1. (2020). The influence of job satisfaction, resilience and work engagement on turnover intention among village doctors in China: across-sectional study.

Zulbahari, N. H., and Alias, R. (2014). Malaysia' s trend of employment turnover: Study on Generation Y. Journal of Modern Marketing Research, 3(1), 1-13. 